\title{
The Challenging Experiences of Nursing Students in South Korea: A Qualitative Inquiry of International Students
}

\author{
Luis M. Dos Santos \\ Woosong Language Institute, Woosong University, South Korea
}

Received September 22, 2020; Revised October 28, 2020; Accepted November 29, 2020

\section{Cite This Paper in the following Citation Styles}

(a): [1] Luis M. Dos Santos, "The Challenging Experiences of Nursing Students in South Korea: A Qualitative Inquiry of International Students," Universal Journal of Educational Research, Vol. 8, No. 12, pp. 7069 - 7077, 2020. DOI: 10.13189/ujer.2020.081274.

(b): Luis M. Dos Santos (2020). The Challenging Experiences of Nursing Students in South Korea: A Qualitative Inquiry of International Students. Universal Journal of Educational Research, 8(12), 7069 - 7077. DOI: 10.13189/ujer.2020.081274.

Copyright $@ 2020$ by authors, all rights reserved. Authors agree that this article remains permanently open access under the terms of the Creative Commons Attribution License 4.0 International License

\begin{abstract}
South Korea is one of the popular destinations for international students to achieve their education. In 2019, due to the development of the Study Korea Project, more than 160 thousand international students were studying at one of the Korean colleges and universities. Due to sociocultural differences (in language, religion, race, and nationality), international students often encounter difficulties caused by discrimination, bias, and stigma during their time in Korea. In other words, while classrooms may be ready for the enrolment of additional international students, local communities, support services, and residents are not. Based on the Social Stigma approach, the researcher collected qualitative interview data of 99 international students from China, Vietnam, Mongolia, Japan and the United States, who are majoring in nursing about their sense-making process and the experiences in Korea. The finding indicated that almost all participants experienced discrimination due to their foreign status, skin colour, language, nationality, and place of origin insides and outsides of the university environment. Furthermore, all expressed negative academic and living experiences in the region and will leave the region once they completed their education. The results demonstrate the necessity for various parties in Korea, including school leaders, government agencies, policymakers, faculty heads, and NGOs, to rethink and reform the country's approach to attracting international students.
\end{abstract}

Keywords International Student, Korean University,
Nursing Education, Nursing Student, Sense-making Process, Stigma

\section{Introduction}

\subsection{Purpose of the Study}

Although South Korea (henceforth referred to as Korea) wants to promote itself as a popular destination for international students, many foreign students and international professionals face difficulties, discrimination, bias, and stigma during their time there [1], [2]. Based on the statistics, nearly 200,000 international students are currently enrolled at Korean universities for either undergraduate or postgraduate education [3], [4]. There is, therefore, a need for an investigation of how these international students make sense of and describe their experience in Korea. Given the large number of different courses that universities offer, and in order to concentrate our results on a particular group, the current study focused on international students studying subjects related to nursing [5].

Although there are no official statistics indicating that the enrolment and major of international students in Korea, nursing is one of the most popular undergraduate majors for both domestic and international students at the 
university level [6]-[8]. Therefore, the current study took nursing undergraduate students as the tools to investigate the sense-making process and experiences, particularly international students in Korea. There are two reasons why this study tends to focus on the problems among nursing students, particularly international students in Korea.

First, nursing is one of the most popular majors in Korea [5]. Every year, a large number of male and female students decide to enrol at one of the nursing programmes at Korean universities. However, a previous study [9] indicated that many nursing graduates decided to leave the nursing profession after their university graduation or a few years after their contract. It becomes one of the biggest problems in public health and human resources systems. In fact, the government invested resources to support the universities and facilities' development. However, many decided to leave their occupation and career pathway. It is important to understand what the problems are.

Second, international students are one of the most important groups in the Korean university system [10]. International students from different parts of the global communities bring different culture, language, understanding, and expectation to the Korean university system. However, due to sociocultural differences (in language, religion, race, and nationality) international students and professionals often encounter difficulties during their time in Korea [1], [11]. In other words, while classrooms may be ready for the enrolment of additional international students, local communities, support services, and residents are not. This study explores the experiences of international students who are currently enrolled at Korean universities. The results demonstrate the necessity for various parties in Korea, including school leaders, government agencies, policymakers, faculty heads, and NGOs, to rethink and reform the country's approach to attracting international students. Based on the ideas from the above sessions, in short, this study was guided by two research questions,

(1) How do international students majoring in nursing make sense of their learning experience in Korea?

(2) How do international students majoring in nursing describe the difficulties, discrimination, bias, and stigma that they encounter as foreigners in Korea?

\subsection{Literature Review}

It has been claimed in a recent report that, worldwide, there are more than five million international students currently studying at higher education institutions outside of their home countries. It is possible that, as a result of globalisation, alongside the expansion of both on-campus studies and distance learning-based programmes, this number may rise to as many as eight million in the near future [12]. Korea is one of the most popular countries among international students outside of the United States, the United Kingdom, and Australia. A recent report indicated that, as of 2019, there were more than 160,000 international students enrolled in Korean universities or graduate school programmes. In 2015, this figure stood at slightly over 91,000 while, by 2016, it had risen to just over 100,000 [3].

Two of the biggest factors driving the increase in the number of international students in recent years have been the effects of the financial crisis and the government's tuition fees policy. The government's prohibition on any non-essential increases in the fees of domestic students has caused private universities and graduate schools to recruit greater numbers of international, full-fee-paying students to make up for the shortfall in their revenue [13].

Another significant factor, which has played a part since the mid-1990s, is Korea's low fertility rate. In 1993, each Korean woman gave birth to 1.654 children. This has since decreased significantly. In 2018, each Korean woman gave birth to only 0.977 children [14]. Due to the resultant decrease in the traditional-age students' population, many universities and graduate schools have found it necessary to recruit additional international students in order to maintain classroom operations.

In the 2000s, the Study Korea Project was launched, a government policy that aimed to promote Korea as a top destination for international students. The project aimed to attract a total of 50,000 international students by the end of 2010, particularly Chinese students. In order to recruit Chinese students, the government coordinated with universities and educational centres, offering scholarships and potential internship programmes to institutions that succeeded in recruiting high numbers of international students. As a result, the number of international students had already exceeded the government's 50,000 targets by the end of 2008 [4].

In 2019, 160,165 (8\%) of Korea's two million students were international students [15]. This represents a huge rise increase since 2015 when the number of international students was slightly over 91,000. Out of the total number of international students in 2019,44.4\% (71,067) were Chinese, 23.4\% were Vietnamese , 4.6\% were Mongolian , $2.7 \%$ were Japanese , and $1.8 \%$ were American [3]. Based on these statistics, it is clear that international students make up a significant portion of the student population in Korean universities.

\subsection{Conceptual Framework}

The current study was guided by the Social Stigma [16][20] conceptual framework. Social Stigma refers to an unacceptable, undesirable, unwanted, and unpleasant experiences, elements, factors, or characteristics individuals have that negatively influence their position(s) in the communities. The negative influences and feelings, therefore, may highly impact the behaviours, mental qualities, and standards of the individuals [21]. Link and Phelan [22] described that social stigma as the elements of 
the following aspects, including labelling the differences between individuals, the cultural differences connecting unwanted behaviours and thinking to the labelled individuals, categorising individuals away from different groups of people (i.e. the international students, the Chinese, the patients etc.), and individuals' status based on their personal characteristics.

Scholars indicated that the majority of the social group(s) in the society as the dominant group(s) who control the values, social standards, perspectives, conceptions, and norms in the dominated society. The idea of social stigma highly impacts how individuals see themselves in society. With the reflection of two previous studies [23], in this case, the dominant majority refers to the Korean people and use the term minorities as foreign and international individuals in Korea [24]. In this study, from the perspectives of international students, the researcher employed the framework of social stigma to explore the research questions and the experiences in Korea.

\section{Materials and Methods}

The researcher employed the qualitative research method [25] as the tool for the data collection and analysis procedures and means. The current research study tends to focus on the in-depth understanding, and personal lived stories of international students in Korea. Such in-depth sharing, lived stories, personal understanding, and life experiences should be collected from qualitative tools, such as interview sessions, focus group activities etc. Therefore, based on the nature and direction of this study, the researcher decided to employ the qualitative research method as the means.

\subsection{Design of the Study: The Application of the Phenomenological Approach}

The researcher decided to employ the phenomenological approach [26] as the methodology for this study. The phenomenological approach allowed the researcher to collect a large-size qualitative data of international students from different schools, perspectives, places of origins, nationalities, and background. With the focus of international students, the background and coverage of these groups of international students might share ideas and lived stories from various background and understanding. More importantly, the researcher tended to collect sharing and voices from participants at different locations and schools (i.e. instead of a single site). Therefore, the application of the phenomenological approach met the abovementioned elements.

Second, as the ideas and populations of international students can be large due to the student enrolment over the years in Korea, it is important to focus on a group of students with a particular background. Based on the nature of this study, international nursing students would be appropriate based on the phenomenological approach.

\subsection{Participants}

Ninety-nine traditional-age nursing international students (i.e. 40 men and 59 women) were invited. All agreed to participate in this study. All the participants were currently enrolled as international students majoring in the nursing-related major at one of the Korean universities. Based on the international students' populations and the results of recruitment, the researcher 50 Chinese international students, 21 Vietnamese international students, 15 Mongolian international students, seven (7) Japanese international students, and six (6) American international students as the participants in this study. Regardless of their VISA status, the participants must be enrolled students and studied at one of the Korean universities for at least a year from the date of the interview.

In order to increase the population and diversity of the participants, the researcher employed the snowball sampling strategy to recruit potential participants. First of all, based on the personal network and connection of the researcher, the researcher could recruit eight qualified participants at the beginning point. The researcher invited the participants with a written invitation with the interview protocol and interview questions. Within the invitation, the participants were asked to invite at least two potential participants with a similar background (i.e. international students who are majoring in nursing). After several rounds of the interview sessions and referral procedures, the researcher reached the saturation status, which might answer the research questions of this study. In sum, the participants must meet all of the following criteria,

$\mathrm{He} / \mathrm{she}$ is currently enrolled at one of the Korean universities;

(1) As an international student (i.e. non-Korean passport holder);

(2) As a nursing student;

(3) For at least one year.

\subsection{Data Collection}

The interview sessions were conducted via social media applications. Although Korea is not a large region, travelling between cities and provinces is not convenient. In order to manage the interview sessions effectively, the researcher decided to employ social media applications (i.e. Whatsapp and Wechat) as the interviewing tool.

The data collection procedure was conducted during the Fall 2019 Semester. As the research tends to collect in-depth information and lived stories from the participants' experiences as international students in Korea, multiple interview sessions were essential. Based on the recommendation of Seidman [27], multiple interview 
sessions do not only increase the validity of the interview data but also increase the in-depth sharing and density of the data. Therefore, the researcher followed the suggestions and invited each participant for three interview sessions. All participants have voluntarily participated in this study. The researcher was the collector and manager of the data. In order to seek meaningful data, first, both open-ended and semi-structured interview questions were created. Each interview session lasted from 60 minutes to 89 minutes.

During the interview sessions, the researcher employed a digital recorder to record the data and sharing from the participants. All participants agreed with the data collection and further analysis.

\subsection{Data Analysis}

Based on the Social Stigma framework [16]-[20] and the data analysis process, in this study, the researcher completed an inductive analysis of the data and categorised the results into structured themes and subthemes. The researcher transcribed the voiced data to written transcripts for reporting. First, the researcher re-read the written transcripts multiple times in order to categorise the groups and themes from the large-size information. Second, the researcher employed the open-coding technique to group different themes and subthemes for reporting. As a result, the first-level themes and subthemes were merged (i.e. 22 themes and 43 subthemes). However, as such large-size themes and subthemes were not appropriate for reporting, the researcher further employed the axial-coding technique to reduce the numbers of the themes and subthemes. Third, after several rounds of data analysis, two themes and four subthemes were merged as the final version.

\subsection{Ethical Considerations}

Protection of participants is the most important part of this study. Participants could withdraw from the study at any time without any punishment. In order to protect the personal identity of the participants, the researcher assigned each participant a pseudonym (e.g. Participant \#1). All signed, unsigned, personal contacts, telephone information, voice data, written transcripts, and related materials were locked in a password-protected cabinet. Only the researcher has the rights to read the information. After the study was completed, the researcher deleted and destroyed the related materials and information immediately in order to protect privacy. The research study was supported and approved by the Woosong University Research Funding 2020 and the Research Team.

\section{Results and Discussions}

All 99 participants expressed negative concerns and feedback about their learning experience as international students (i.e. in the field nursing) in Korea, as well as about the difficulties, discrimination, bias, and stigma that accompanied it, including both inside and outside of the university environment. All of the participants expressed regret over their decision to come to Korea for their university education. All intend to leave Korea once they have completed their education as none of them are satisfied with their learning or living experiences. With the reflection of a previous study [28], although Korea wants to develop the intercultural environment and living standard due to the development of globalisation, the social development and overall performance of the local Korean residents are not ready for such multiculturalism. Therefore, although the government established plans for international professionals, the communities and their members are not ready to exercise the plans from the government [29]. For the detail of the themes and subthemes, please refer to Table 1.

Table 1. Themes and Subthemes

\begin{tabular}{|c|c|l|}
\hline \multicolumn{3}{|c|}{ Themes and Subthemes } \\
\hline 3.1. & & $\begin{array}{l}\text { Situation Outsides of the University: } \\
\text { Discrimination based on my Personal } \\
\text { Characteristics }\end{array}$ \\
\hline & 3.1 .1$. & Skin Colour is my Sins in Korea \\
\hline & 3.1 .2$. & My Place of Origin and my Nationality \\
\hline 3.2. & 3.1 .3$. & $\begin{array}{l}\text { Spoken Languages: Limitations of the } \\
\text { Korean Language Proficiency }\end{array}$ \\
\hline & 3.2 .1$. & $\begin{array}{l}\text { Situation Insides of the University: } \\
\text { Unfairness between Students }\end{array}$ \\
\hline & & $\begin{array}{l}\text { The Lack of Support Services: } \\
\text { Languages and Nationalities }\end{array}$ \\
\hline
\end{tabular}

\subsection{Situation Outsides of the University: Discrimination Based on my Personal Characteristics}

I am not smart, but I deserve to be respected as a human being...but I was being judged and being discriminated to death by the Korean people...(Participant\#3, Female)

Discrimination is not uncommon in Korea. Previous studies [30] have indicated that Korean people like to judge others based on their own expectations and social norms [31]. From kindergarten to the workplace, people judge and discriminate against minorities and people with special needs as a means of boosting their own status [32]. This judgement and discrimination do not apply only to local Korean residents but also to international students and foreign professionals[16]-[20] . All participants in this study claimed to have experienced various levels of discrimination and judgement from Korean people in the local community based on their skin colour, nationality, and spoken languages. These discriminations and biases caused participants significant difficulties and distresses [20]. More importantly, these difficulties significantly influenced their learning and living experiences while 
living in Korea as international students [16]-[20].

\subsubsection{Skin Colour is My Sins in Korea}

According to a recent report [33], there are more than 2.5 million foreigners in Korea, including 701,098 Chinese (i.e., both Chinese and Chinese-Korean), 224,518 Vietnamese, 209,909 Thais, 156,982 Americans, 86,196 Japanese, 75,320 Uzbeks, 62,398 Filipinos, 61,427 Russians, 48,854 Indonesians, 48,185 Mongolians, and 47,565 Cambodians. Although Chinese, Japanese, and Vietnamese people share similar skin colours and cultural backgrounds with Koreans, participants from these countries still faced discrimination. From the perspectives of other East Asian participants (i.e., Cambodian, Chinese, Japanese, Mongolian, Thais, and Vietnamese), all claimed that they were discriminated against because of their darker skin colour. A participant said,

I love sport and outdoor activities...but the Korean people call me farmer and blue-collar labourer...they asked me to clean up the street and called me rural boy because of my skin colour...In East Asia, people don't like people with darker skin colour as they look down on blue-collar workers...and worship white-collar professionals...due to my skin colour, I was being stigmatised...(Participant\#44, Male)

Ethnic Chinese-Korean participants claimed to have had similar experiences, even though they are technically Korean citizens. A participant said,

I am a Chinese-Korean who speaks the Korean language with a Northern Korean accent...the local people continued to look down me because of my dark skin colour...I used to work on my family's farm in China...but I returned back to my homeland...Korea...for university...but these people don't care; they just call me farming boy... (Participant\#23, Female)

Further significant information was provided by Uzbek participants, many of whom were eligible to receive additional support or scholarships for their studies as a result of government policies like the Study Korea Project [4]. With the reflection of a previous study [34], even though the government has established policies like these to support foreign students, it is clear that local communities are not impressed by the resulting influx of foreign students. More importantly, racism and exceed behaviours due to the cultural differences between the foreign and Korean students were experienced during their (i.e. international students') learning experiences in Korea [35]. Participants who had a different skin colour shared stories about their experiences of discrimination and stigma [16]-[20]:

Some local residents like to kick my door in the middle of the night for fun...many of my foreign classmates and even professors face similar tricks, such as kicking doors, stealing letters and books, oral harassments from others, etc...I was asked to leave Korea almost once per week for three years... (Participant\#31, Female)

In short, with the reflection of some previous studies, all 99 participants claimed to have experienced various instances of discrimination, bias, and stigma [16]-[20] due to their skin colour (i.e., non-Korean and darker skin colours) [34]. It was demonstrated in a previous study that non-Korean professionals typically suffer from high levels of stress as a result of discrimination based on their biological characteristics [36]. With the reflection of some previous studies [37], the findings from the present study show that such difficulties are encountered not only by non-Korean individuals but also by Chinese-Korean individuals [1], [32].

\subsubsection{My Place of Origin and my Nationality}

Discrimination [16]-[20] based on nationality includes treating individuals unfavourably due to their place of origin, ethnicity, or cultural background in Korea [35]. Discrimination can also occur because an individual is married or divorced to a person with a certain nationality, skin colour, family background, or victim status [34]. In this study, 11 participants were married, of whom three were married to a Korean person. These three married participants experienced discrimination because of their marriage status. They claimed that many local Korean people see them as taking advantage of Korean public funds and attempting to secure benefits through their international marriage. A participant said,

I did community services at a senior centre because of my university major and my personal contribution...some senior called me a Muslim thief because I am married to a Korean man...I gained my F-6 Visa (indefinite leave to remain via marriage) because I have rights...but these people called me a thief of their country's public funds...(Participant\#48, Female)

With the reflection of a previous study [38], although non-Korean individuals have been married or lived in Korea for decades, many Korean people do not recognise them as Korean due to their gender, racial, and class lines [16]-[20]. More importantly, the results from the participants further confirmed the results of two previous studies [38] about Korean people always believe foreign brides like to take the advantages from the Korean spouse due to their political intention. In this study, although the participants (i.e. nursing university students) tried their best to learn and accept the Korean culture and expectations, the experiences were negative [39].

With the reflection of a previous study [39], a group of participants from south-eastern Asian countries claimed to have had negative experiences as a result of their nationalities and the perceived characteristics of their 
countries. For example, several Thai participants were called to farm rice in Korea as Thailand is an agricultural community. A participant said,

...not just once, but at least ten times per year...Korean people asked me to farm rice in the plantations because of my Thai nationality...Korean people love to categorise people based on their nationality and the characteristics of their country (Participant\#1, Female)

Similar experiences were shared by a group of Chinese participants. They claimed that Korean people loved to call them by the names of Chinese brands. Two said,

Korean people called me XiaoMi or Huawei or Beijing duck...but I have a name...my name is XiaoMi...This is discrimination....but they called us... food names to make fun of foreign students...I used to study in Japan and the United States...I never experienced such stigma and discrimination from others there [i.e., Japanese and American people] (Participant\#21, Female)

I was called Chinese-Kimchi (salted and fermented vegetables) because of my Chinese-Korean nationality and status...I am not here for fun...I am here to study and for personal development...(Participant\#80, Female)

\subsubsection{Spoken Languages: Limitations of the Korean Language Proficiency}

Due to globalisation and the development of the Study Korea Project, many universities and graduate schools have established English-medium programmes [4], [32]. Students applying to these programmes do not need to have any proficiency in the Korean language. According to previous studies [40]-[42], many Korean colleges and universities decided to establish English-based programmes and courses for international students who do not have Korean proficiencies for education. Although Korean language proficiency is not a requirement of the university education, many participants in this study decided to learn some basic Korean for personal development purposes. Although knowledge of the Korean language did help participants to interact with members of the local community, many also faced discrimination as a result of their accent or low level of proficiency [43]. A group of participants with only basic-levels of language proficiency claimed that Korean people liked to make fun of them and to mimic their attempts at speaking the language,

I cannot pronounce the roundedness in Korean because my native language does not have these voices...but the Korean people like to repeat my mistakes and make fun of these errors...some of them pretended they cannot understand my sentences... (Participant\#89, Male)
I am not here to learn Korean but my major...but Korean people asked me to leave their country because I do not understand a word in Korean...the bus driver even called me a Muslim dog because of my accent... (Participant\#67, Female)

In short, although the government has established policies that aim to encourage the enrolment of international students at Korean universities, as well as the return of Chinese-Korean professionals to their homeland, there is nevertheless a disconnect between government aspirations to create a welcoming environment for foreign students and the attitudes and perspectives of local residents. International students and professionals continue to face discrimination, bias, and stigma due to their personal characteristics. As indicated by the findings of previous studies, regardless of their VISA status, international professionals face unfairness because of their foreign status. Although one of the purposes of the Study Korea project was to promote Korea as a destination that welcomed global professionals and learners, local communities were unimpressed, and this has severely limited the achievements of this governmental project [16]-[20].

\subsection{Situation Insides of the University: Unfairness between Students}

Besides the difficulties that they encountered in the local community, many participants also faced discrimination, bias, and stigma within their university environments [16][20]. Previous studies [31], [44] have indicated that Korean people tend to judge people based on characteristics such as nationality, background, culture, language, skin colour, and income [26], [31]. All participants in the present study experienced negative discrimination and attitudes from their instructors and classmates. These can be categorised as falling into various subthemes of discrimination, including the unfairness shown to international students by instructors and classmates and discrimination based on nationality.

Previous studies [40], [45] have emphasised that, due to concerns about globalisation, Korean universities have made efforts to ensure that most of their academic programmes can be taught in English, making them particularly open to the enrolment of international students. In addition, Korean secondary graduates are required to pass an English exam in order to enter university. Therefore, it might be reasonably expected that both instructors and students should have intermediate-level English-language proficiency [34]. However, based on participants' responses, only a few staff and students at their universities use English for communication. More importantly, both staff and students use language as a means to discriminate [16]-[20] against non-Korean participants: 
The university admission office did not ask us to have any Korean language proficiency, and nor was this a requirement for graduation, as this program is taught in English. But our professors and classmates cannot speak a word in English...not even basic present tense...As the materials are all written in Korean...I have a hard time completing my education... (Participant\#72, Male)

\subsubsection{The Lack of Support Services: Languages and Nationalities}

According to a previous study, although some students expressed positive academic and living experiences in Korea, many indicated negative experiences and comments of their experiences in Korea [35]. Based on the current study, almost all participants claimed that they faced discrimination, bias, and stigma [16]-[20] due to their foreign status and nationalities. While many tried to convince themselves that this discrimination was not real, they could not ignore the fact that they continued to have negative experiences both at university and within the local community [46]. As well as being treated unfairly by instructors and classmates, many also found it difficult to use administrative and students' services due to language barriers and discrimination. One participant said,

\section{I wanted to use the mental counselling service because I was being bullied by my Korean classmates... I explained my situation to the Korean counsellor, and he told me not to blame the Korean environment or my Korean classmates. As a foreigner...I have to accept that this is Korean culture...(Participant\#3, Female)}

Other participants shared similar experiences. Several claimed that in the library, the gatekeepers always allow Korean students to enter without any key cards but that foreigners are required to show both government-issued ID and student card to gain entry. Many indicated that such discriminatory practices limited their motivation to study. A participant said,

\begin{abstract}
There is one set of rules for foreigners and another for local Korean students...Korean students are allowed additional copy papers and follow easier rules; but international students are punished because of our nationality...my classmate from Africa had an even harder time then myself... (Participant\#21, Female)
\end{abstract}

In conclusion, based on the results from the study, all experienced negative experiences, feedback, opinions due to their biological elements, personalities, and personal characteristics (i.e. social stigma) [16]-[20]. Although all want to understand and merge their standard and behaviours into the Korean communities, all continued to experience racism, discrimination, hate speech, and sexism insides and outsides of the university environment, including their interned sites. Although the Korean government [4] always encouraged the development of multiculturalism and intercultural developments [47], based on the results of the study, none expressed positive feedback from the plans and schemes from the governments, schools, and local Korean residents during their time in Korea. As a result, due to the negative experiences, many will leave Korea after their university graduation.

\section{Conclusion and Implication of the Study}

In conclusion, based on the framework of the social stigma approach, Korea is one of the popular educational destinations for international students and professionals to develop their academic experience and career development in the East Asian region. The Korean government also established the Korea Study Project in 2004 in order to attach international students with different background, language, religion, nationalities, and expectations from all parts of the global communities to increase the diversity of the Korean colleges and universities. However, based on the results of this study, there are still many challenges and rooms of improvements for the developments. Based on the results, the researcher may provide three recommendations to the government departments, school leaders, community leaders, policymakers, counsellors, teachers, and researchers to reform the current policies for international students, professionals, and workers in Korea.

First, the Korean government should provide multicultural and intercultural education and studies for the youths to understand the ideas of cultural diversity in the global community. In fact, the ideas and developments of globalisation do not only limit to China and Japan, but Korea should also experience the development of globalisation in the East Asian region. It is important to provide additional training and studies in order to establish the open-minded behaviours and understanding for the youths and the next generations.

Second, it is important for the Korean communities to understand international students, professionals, and workers are essential in the region. Based on the previous studies, foreigners are encouraged to come to Korea in order to satisfy the needs and demands of human resources and manpower problems. Such human resources shortages, however, are not unique in Korea, but other developed countries, such as Japan. If discrimination and stigma continue, skilled professionals will leave Korea to other countries and regions.

Third, although the Korea Study Project encouraged international students for Korean education, many university programmes and services are not ready for any foreign language services, such as English services and communications. The inconvenience, however, highly limited the satisfaction and experience of international 
students in Korea. More importantly, the skilled, multicultural, and multilingual graduates will leave the region immediately after their graduation. The Korean government, however, would lose the skilled and trained professionals who should work in the region.

\section{Acknowledgements}

This study was supported by Woosong University Academic Research Funding 2020.

\section{REFERENCES}

[1] L. M. Dos Santos, "Stress, burnout, and turnover issues of Black expatriate education professionals in South Korea: Social biases, discrimination, and workplace bullying,” Int. $J$. Environ. Res. Public Health, vol. 17, no. 11, p. 3851, 2020, doi: 10.3390/ijerph17113851.

[2] L. M. Dos Santos, "I am a nursing student but hate nursing: The East Asian perspectives between social expectation and social context,” Int. J. Environ. Res. Public Health, vol. 17, no. 5, p. 2608, 2020, doi: 10.3390/ijerph17072608.

[3] M. Koh and M. Kim, "Number of international students rises to all-time high in South Korea," Maeil Business News Korea, Seoul, South Korea, Aug. 30, 2019.

[4] “Education of international students," Ministry of Education National Institute for International Education, 2020. https://www.studyinkorea.go.kr/en/sub/overseas_info/korea _edu/edu_student.do (accessed Sep. 20, 2020).

[5] L. M. Dos Santos, "How does COVID-19 pandemic influence the sense of belonging and decision-making process of nursing students: The study of nursing students' experiences,” Int. J. Environ. Res. Public Health, vol. 17, no. 15, p. 5603, Aug. 2020, doi: 10.3390/ijerph17155603.

[6] I. Kim, "The Role of Self-Efficacy and Social Support in the Relationship between Emotional Labor and Burn out, Turn over Intention among Hospital Nurses,” J. Korean Acad. Nurs. Adm., vol. 15, no. 4, pp. 515-526, 2009.

[7] Y. Yang, "A study on Burnout, Emotional labor, and Self-efficacy in Nurses,” Korean Acad. Nurs. Adm., vol. 17, no. 4, pp. 423-463, 2011.

[8] S. R. Shin, S. K.R., and C. Y. Li, "Nursing education system in Korea, China and the United States of America and its future directions,” J. Korean Acad. Nurs., vol. 32, no. 7, pp. 949-959, 2002.

[9] H. Chang, D. Friesner, T. Chu, T. Huang, Y. Liao, and C. Teng, "The impact of burnout on self-efficacy, outcome expectations, career interest and nurse turnover," J. Adv. Nurs., vol. 74, no. 11, pp. 2555-2565, Nov. 2018, doi: 10.1111/jan.13776.

[10] A. M. Alemu and J. Cordier, "Factors influencing international student satisfaction in Korean universities," Int. J. Educ. Dev., vol. 57, no. 1, pp. 54-64, Nov. 2017, doi: 10.1016/j.ijedudev.2017.08.006.
[11] L. M. Dos santos, "Becoming university language teachers in South Korea: The application of the interpretative phenomenological analysis and social cognitive career theory,” J. Educ. e-Learning Res., vol. 7, no. 3, pp. 250-257, 2020, doi: 10.20448/journal.509.2020.73.250.257.

[12] OECD, "Education at a glance 2017: OECD indicators," Paris, France, 2017.

[13] M. Yeom, "Understanding the internationalization of higher education in South Korea with different theories of development," in Contesting Globalization and Internationalization of Higher Education, Cham: Springer International Publishing, 2019, pp. 17-32.

[14] The World Bank, "Fertility rate, total: Republic of Korea," Washington, DC, 2020. [Online]. Available: https://data.worldbank.org/indicator/SP.DYN.TFRT.IN?loc ations $=\mathrm{KR}$.

[15] W. So, "Number of enrolled university students in South Korea 2011-2019,” New York, NY, 2020. [Online]. Available:

https://www.statista.com/statistics/710612/south-korea-enro lled-university-students-number/.

[16] H. Tajfel, “Cognitive aspects of prejudice,” J. Biosoc. Sci., vol. 1, no. S1, pp. 173-191, Sep. 1969, doi: 10.1017/S0021932000023336.

[17] H. Tajfel and J. C. Turner, "The social identity theory of intergroup behaviours," in Psychology of intergroup relations, Chicago, IL: Nelson-Hall Publishers, 1986, pp. 724.

[18] H. Tajfel, Social identity and intergroup relations. Cambridge, UK: Cambridge University Press, 2010.

[19] H. Tajfel, “Quantitative Judgement in Social percetion,” Br. J. Psychol., vol. 50, no. 1, pp. 16-29, Feb. 1959, doi: 10.1111/j.2044-8295.1959.tb00677.x.

[20] E. Goffman, Stigma: Notes on the management of spoiled identity. Englewood Cliffs, N.J.: Prentice-Hall, 1963.

[21] L. M. Dos Santos, "Postgraduate international students' living and learning experience at a public university in British Columbia,” Alberta J. Educ. Res., vol. 64, no. 3, pp. 318-321, 2018.

[22] B. Link and J. Phelan, “Conceptualizing stigma,” Annu. Rev. Sociol., vol. 27, pp. 363-385, 2001.

[23] R. Shinnar, "Coping with negative social identity: The case of mexican immigrants,” J. Soc. Psychol., vol. 148, no. X, pp. 553-576, 2008.

[24] A. Hurtado, P. Gurin, and T. Peng, "Social identities-A framework for studying the adaptations of immigrants and ethnics: The adaptations of Mexicans in the United States," Soc. Probl., vol. 41, no. 1, pp. 129-151, Feb. 1994, doi: $10.2307 / 3096846$.

[25] K. H. Tang and L. M. Dos Santos, “A brief discussion and application of interpretative phenomenological analysis in the field of health science and public health,” Int. J. Learn. Dev., vol. 7, no. 3, pp. 123-132, Aug. 2017, doi: 10.5296/ijld.v7i3.11494.

[26] C. Moustakas, Phenomenological research methods. Thousand Oaks, CA: Sage, 1994. 
[27] I. Seidman, Interviewing as qualitative research: A guide for researchers in education and the social sciences, 4th ed. New York, NY: Teachers College Press, 2013.

[28] S. Shen, "The bibimbap migration theory? Challenges of Korea's multicultural mix and social integration development," J. Int. Migr. Integr., vol. 18, no. 3, pp. 771789, Aug. 2017, doi: 10.1007/s12134-016-0489-6.

[29] A. Kim, "Global migration and South Korea: foreign workers, foreign brides, and the making of a multicultural society,” Ethn. Racial Stud., vol. 32, no. 1, pp. 70-92, 2009.

[30] L. M. Dos Santos, "Stress, burnout, and low self-efficacy of nursing professionals: A qualitative inquiry," Healthcare, vol. 8, no. 4, p. 424, Oct. 2020, doi: 10.3390/healthcare8040424.

[31] E. Kim and H. Park, "Perceived gender discrimination, belief in a just world, self-esteem, and depression in Korean working women: A moderated mediation model,” Womens. Stud. Int. Forum, vol. 69, no. July-August, pp. 143-150, Jul. 2018, doi: 10.1016/j.wsif.2018.06.006.

[32] H. N. Suh, L. Y. Flores, and K. T. Wang, "Perceived discrimination, ethnic identity, and mental distress among Asian international students in Korea," J. Cross. Cult. Psychol., vol. 50, no. 8, pp. 991-1007, Sep. 2019, doi: $10.1177 / 0022022119874433$.

[33] "Number of foreign residents in Korea tops 2.5 million," Yonhap News Agency, Seoul, South Korea, 2020.

[34] J. Kim, "Racism, equity, and quality of education for international students in South Korean higher education institutes,” Front. Educ. China, vol. 11, no. 3, pp. 338-355, 2016, doi: 10.3868/s110-005-016-0027-3.

[35] J. Kim and H. Jeon, "Anti-multiculturalism and the future direction of multicultural education in South Korea," Curric. Perspect., vol. 37, no. 2, pp. 181-189, Oct. 2017, doi: 10.1007/s41297-017-0025-7.

[36] F. L. Collins and S. Shubin, "Migrant times beyond the life course: The temporalities of foreign English teachers in South Korea,” Geoforum, vol. 62, no. 1, pp. 96-104, Jun. 2015, doi: 10.1016/j.geoforum.2015.04.002.

[37] L. M. Dos Santos, "Male nursing practitioners and nursing educators: The relationship between childhood experience, social stigma, and social bias,” Int. J. Environ. Res. Public Health, vol. 17, no. 14, p. 4959, Jul. 2020, doi: 10.3390/ijerph17144959.

[38] T. Lim, "Rethinking belongingness in Korea: Transnational migration, 'migrant marriages' and the politics of multiculturalism,” Pac. Aff., vol. 83, no. 1, pp. 51-71, Mar. 2010, doi: $10.5509 / 201083151$.

[39] Y. Kim, I. Son, D. Wie, C. Muntaner, H. Kim, and S.-S. Kim, "Don't ask for fair treatment? A gender analysis of ethnic discrimination, response to discrimination, and self-rated health among marriage migrants in South Korea," Int. J. Equity Health, vol. 15, no. 1, p. 112, Dec. 2016, doi: 10.1186/s12939-016-0396-7.

[40] J. Kim, B. Tatar, and J. Choi, "Emerging culture of English-medium instruction in Korea: experiences of Korean and international students," Lang. Intercult. Commun., vol. 14, no. 4, pp. 441-459, Oct. 2014, doi: 10.1080/14708477.2014.946038.

[41] E. G. Kim, "English medium instruction in Korean higher education: Challenges and future directions," in English Medium Instruction in Higher Education in Asia-Pacific, B. Fenton-Smith, P. Humphreys, and I. Walkinshaw, Eds. Springer, 2017, pp. 53-69.

[42] J. S. Lee and K. Lee, "Perceptions of English as an international language by Korean English-major and non-English-major students," J. Multiling. Multicult. Dev., vol. 40, no. 1, pp. 76-89, Jan. 2019, doi: $10.1080 / 01434632.2018 .1480628$.

[43] S. Ahn and H. Kang, "South Korean university students' perceptions of different English varieties and their contribution to the learning of English as a foreign language," J. Multiling. Multicult. Dev., vol. 38, no. 8, pp. 712-725, Sep. 2017, doi: 10.1080/01434632.2016.1242595.

[44] K. O. Seol, H. C. Yoo, R. M. Lee, J. E. Park, and Y. Kyeong, "Racial and ethnic socialization as moderators of racial discrimination and school adjustment of adopted and nonadopted Korean American adolescents.," J. Couns. Psychol., vol. 63, no. 3, pp. 294-306, Apr. 2016, doi: 10.1037/cou0000120.

[45] Y. K. Jeong, “A chapter of English teachingin Korea," English Today, vol. 20, no. 2, pp. 40-46, 2004, doi: 10.1017/S026607840400207X.

[46] S. Y. Bae and H. Song, "Intercultural sensitivity and tourism patterns among international students in Korea: using a latent profile analysis," Asia Pacific J. Tour. Res., vol. 22, no. 4, pp. 436-448, Apr. 2017, doi: 10.1080/10941665.2016.12 76087.

[47] R. J. Moon, "Internationalisation without cultural diversity? Higher education in Korea,” Comp. Educ., vol. 52, no. 1, pp. 91-108, Jan. 2016, doi: 10.1080/03050068.2015.1125679. 